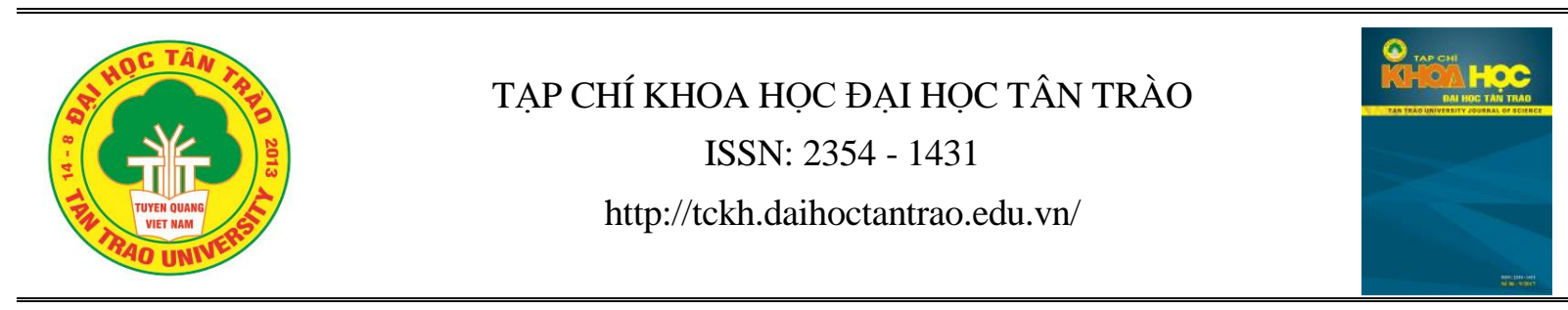

\title{
QUAN HỆ MỸ - ĐÀI LOAN TRONG NƯA ĐẦU NHIẸM KỲ CỦA TỔNG THỐNG DONALD TRUMP (2017 - 2018)
}

Nguyễn Đức Mạnh ${ }^{a^{*}}$

${ }^{a}$ Học viện Chính trị Công an nhân dân

*Email: ducmanhnguyen1998@gmail.com

\section{Thông tin bài viết}

Ngày nhận bài:

$4 / 5 / 2020$

Ngày duyệt đăng:

$10 / 6 / 2020$

Tù khóa:

Mỹ, Đài Loan, Donald

Trump, Thái Anh Văn, quan

hệ đối ngoại.

\section{Tóm tắt}

Quan hệ Mỹ - Đài Loan luôn là mối quan hệ ngoại giao được nhiều đời Tổng thống Mỹ quan tâm. Dưới thời Tổng thống Donald Trump, quan hệ Mỹ - Đài Loan tiếp tục được củng cố và phát triển sâu sắc, thậm chí có những đột phá so với trước. Trong phạm vi bài viết, tác giả phân tích những tiến triển trong mối quan hệ Mỹ - Đài Loan trong nửa đầu nhiệm kỳ của Tổng thống Donald Trump (2017-2018). Từ đó, tác giả đưa ra một số lý do giải thích cho những tiến triển trên.

\section{1. Đặt vấn đề}

Quan hệ Mỹ - Đài Loan luôn là mối quan hệ ngoại giao được nhiều đời Tổng thống Mỹ quan tâm. Ngay sau khi chiến thắng cuộc bầu cử Tổng thống ồn ào và đầy tranh cãi, đặc biệt sau khi nắm quyền (20/01/2017), Tổng thống Donald Trump đã có những động thái nhằm củng cố mối quan hệ này. Có thể nói, mối quan hệ Mỹ - Đài Loan dưới thời Tổng thống Donald Trump có những tiến triển mạnh mẽ. Nhận định này được tác giả làm rõ trong nửa đầu nhiệm kỳ Tổng thống của ông Donald Trump (2017 2018). Mặc dù mới hai năm nhưng nó đã khắc họa đầy đủ quan điểm và những chỉ đạo cụ thể của ông Trump trong mối quan hệ Mỹ - Đài Loan.

\section{Nội dung nghiên cứu}

Trước năm 1949, Mỹ và Trung Hoa Dân quốc là hai đồng minh gần gũi. Từ năm 1949 đến nửa đầu thập niên 70 của thế kỷ XX, Mỹ vẫn duy trì quan hệ ngoại giao chính thức và công nhận chính quyền Trung Hoa Dân quốc là đại biểu hợp pháp duy nhất của Trung Quốc đại lục tại Liên Hợp Quốc (đến năm 1971). Tuy nhiên, đến năm 1979, Mỹ cắt đứt quan hệ ngoại giao với chính quyền ở đảo Đài Loan. Từ đó, quan hệ Mỹ - Đài Loan chuyển sang giai đoạn quan

hệ không chính thức dựa trên Đạo luật Quan hệ Đài Loan. Mặc dù vậy, mối quan hệ này luôn được chính quyền Mỹ quan tâm từ đó đến nay.

Kể từ ngày 20/01/2017, ông Donald Trump chính thức trở thành Tổng thống thứ 45 của Mỹ sau cuộc bầu cử ồn ào và đầy tranh cãi. Với góc nhìn của một vị Tổng thống - tỷ phú, ông đã có nhiều quyết định chưa từng có tiền lệ trong lịch sử nước Mỹ. Vấn đề quan hệ với Đài Loan cũng nằm trong quỹ đạo khác thường đó dưới thời của ông Trump. Tuy nhiên, mối quan hệ Mỹ - Đài Loan không chỉ thuần túy là kế thừa và phát huy mối quan hệ đồng minh truyền thống có từ các đời Tổng thống tiền nhiệm mà giải quyết mối quan hệ Mỹ - Đài Loan đối với ông Trump là một chiến thuật quan trọng trong cuộc cạnh tranh chiến lược Mỹ - Trung. Hiện nay, Trung Quốc đang thay đổi phương châm từ "giấu mình chờ thời" sang "phấn đấu để thành công”, hứa hẹn một Trung Quốc sẽ "phất cờ” và cạnh tranh vị trí số một với Mỹ. Do đó, đối với ông Trump, củng cố mối quan hệ Mỹ - Đài Loan nhằm kiềm chề Trung Quốc đại lục, không để Trung Quốc đại lục vượt mặt Mỹ. Trong nỗ lực kiềm chế Trung Quốc đại lục, Mỹ tỏ ra rất quyết tâm vì nếu để 
tình huống xấu nhất xảy ra thì Mỹ sẽ không bao giờ còn cơ hội để duy trì trật tự thế giới do mình đứng đầu nữa.

Có thể thấy rằng, trong nửa đầu nhiệm kỳ Tổng thống Donald Trump (2017-2018), mối quan hệ giữa Mỹ và chính quyền đảo Đài Loan đã có những bước phát triển vượt bậc và cả động thái chưa từng có tiền lệ. Nhận định này đưa ra dựa trên những khía cạnh sau:

Khía cạnh thú nhất, Mỹ đã có những hoạt động ngoại giao vượt ra ngoài khuôn khổ thông thường:

(1) Ngay sau khi ông Donald Trump đắc cử Tổng thống, nhóm tham mưu thân cận đã cố vấn cho ông nhận cuộc điện thoại chúc mừng từ bà Thái Anh Văn người đứng đầu chính quyền Đài Loan. Cuộc điện đàm này đã diễn ra trên thực tế $(02 / 12 / 2016)$ và đây là lần đầu tiên một Tổng thống Mỹ có giao tiếp chính thức với người đứng đầu đảo Đài Loan kể từ năm 1979.

Điều đặc biệt không chỉ dừng lại ở đó, trong cuộc điện đàm kéo dài 10 phút với bà Thái Anh Văn, Tổng thống đắc cử Donald Trump đã nói rằng, "không nhất thiết" phải là "Một Trung Quốc" [1]. Quan điểm này của ông Trump đã động chạm đến nguyên tắc "Một Trung Quốc" mà nước Mỹ đã nhiều lần cam kết với Đại lục thông qua các Thông cáo 1972, 1979, 1982. Cuộc điện đàm này đã khiến Tổng thống Donald Trump nhận được sự phản ứng dữ dội từ Đại lục và làm cho chính quyền sắp mãn nhiệm của Tổng thống Barack Obama phải vất vả để giải trình với Trung Quốc đại lục về những phát ngôn của Tổng thống đắc cử.

(2) Ngày 12/6/2018, Mỹ đã tổ chức khánh thành trụ sở mới của Viện Hoa Kỳ ở Đài Loan, một cơ quan trên thực tế đóng vai trò như đại sứ quán của Mỹ tại Đài Loan. Công trình này có kinh phí xây dựng lên đến khoảng 250 triệu USD và bắt đầu mở cửa đón công dân từ tháng $4 / 2019$. Đến dự sự kiện khánh thành trụ sở mới có nguyên Chủ tịch Hạ viện Mỹ Paul Ryan và nhiều quan chức cấp cao làm việc trong ngành ngoại giao của nước Mỹ. Nếu so sánh với các cơ quan ngoại giao của Mỹ ở nước ngoài, Viện Hoa Kỳ ở Đài Loan khiến nhiều đại sứ quán phải ghen tỵ về quy mô và mức độ được bảo vệ nghiêm ngặt từ Chính phủ. Nơi đây được xây chìm trong một ngọn đồi ở Đài Bắc và được thủy quân lục chiến Mỹ thường xuyên tuần tra canh gác và được bảo vệ cẩn trọng.

So với các chính quyền tiền nhiệm, chính quyền của Tổng thống Donald Trump đã đi xa hơn so với các cử chỉ ngoại giao thông thường, thậm chí tạo sự đột biến khi hoài nghi về nguyên tắc "Một Trung Quốc" - một trong những nguyên tắc nền tảng trong mối quan hệ giữa Mỹ và Trung Quốc đại lục. Nếu như tiếp xúc ngoại giao dưới thời các Tổng thống tiền nhiệm rất khiêm tốn thì dưới thời Tổng thống Donald Trump đã có sự tiếp xúc giữa hai người đứng đầu chính quyền. Những cử chỉ ngoại giao ấy cho thấy tầm quan trọng của Đài Loan đối với Mỹ và là bước khởi động cho sự phát triển mạnh mẽ trong quan hệ giữa Mỹ và chính quyền đảo Đài Loan dưới thời Tổng thống Donald Trump.

Khía cạnh thứ hai, sự ra đời của các đạo luật nhằm củng cố mối quan hệ giữa Mỹ với chính quyền đảo Đài Loan:

(1) Đạo luật du lịch Đài Loan đã được Tổng thống Trump thông qua (3/2018) nhằm kêu gọi có thêm những trao đổi chính thức với Đài Loan. Sau đó không lâu, Phó Trợ lý Ngoại trưởng Mỹ phụ trách vấn đề Đông Á và Thái Bình Dương Alex Wong thăm Đài Loan.

(2) Đạo luật phê chuẩn chính sách quốc phòng John S. McCain được thông qua vào tháng $8 / 2018$. Sự ra đời của đạo luật này thể hiện sự ủng hộ của hai đảng trong Quốc hội và các quan chức quốc phòng Mỹ dành cho Đài Loan. Đạo luật này hỗ trợ thêm cho mối quan hệ quân sự với Đài Loan, đồng thời yêu cầu báo cáo thường niên về tầm ảnh hưởng của Đại lục trong lĩnh vực truyền thông, văn hóa, kinh doanh và học thuật với Đài Loan.

(3) Đạo luật Sáng kiến tái đảm bảo châu Á được ký vào tháng 12/2018 nhằm tái xác nhận cam kết của Mỹ đối với Đài Loan. Điều này được củng cố bằng một nghị quyết được ban bố cùng thời điểm, tái xác nhận Đạo luật quan hệ Đài Loan và 6 đảm bảo.

Các văn bản pháp lý trên không chỉ được ban hành bởi Tổng thống Mỹ mà còn từ lưỡng viện Quốc hội Mỹ. Đối với vấn đề Đài Loan, cả chính quyền và cơ quan lập pháp Mỹ đều ra sức ủng hộ và thúc đẩy các cơ chế pháp lý cho hành động của Mỹ trong những tình huống bất ngờ trong tương lai. Trong nửa đầu nhiệm kỳ của mình, nếu Tổng thống Trump đã vấp phải sự phản đối kịch liệt của Quốc hội trên phần lớn các vấn đề, như chăm sóc sức khỏe, bức tường biên giới... thì riêng vấn đề Đài Loan, ông luôn nhận được sự thống nhất cao.

Các đạo luật được thông qua kể từ khi ông Donald Trump lên cầm quyền đã tạo cơ sở ngày càng mạnh mẽ cho mối quan hệ đồng minh Mỹ - Đài Loan, nhiều văn bản có ý nghĩa quan trọng để chính quyền đảo Đài Loan củng cố vị thế chính trị của mình. 
Khía cạnh thú $b a$, Mỹ đã thay đổi phương thức và thúc đẩy hoạt động hợp tác quân sự với Đài Loan:

(1) Sự thay đổi trong phương thức bán vũ khí của Mỹ với Đài Loan.

Từ khi lên nắm quền vào tháng $01 / 2017$, Tổng thống Donald Trump đã thông báo với Quốc hội 3 thương vụ bán vũ khí cho Đài Loan, tổng cộng 2,75 tỷ USD. Về nội dung, các thương vụ này gồm dự án bán vũ khí cho Đài Loan và dự án linh kiện máy bay chiến đấu cùng dịch vụ hậu cần mà chính quyền tiền nhiệm chưa hoàn thành, tập trung nâng cao sức mạnh không quân và năng lực tác chiến bất đối xứng.

Điều đáng chú ý ở đây là chính quyền Trump đã thay đổi phương thức bán cả gói dưới thời Obama, khôi phục hình thức số lượng ít trong nhiều đợt dưới thời George $\mathrm{W}$. Bush của Đảng Cộng hòa nhằm thực hiện bình thường hóa việc bán vũ khí cho Đài Loan. Bên cạnh đó, Mỹ đã thay đổi phương thức bán vũ khí cho Đài Loan thể hiện đặc điểm mới là chính quyền và doanh nghiệp cùng thực hiện. Theo truyền thống, Mỹ bán vũ khí cho Đài Loan theo phương thức mua bán "giữa hai chính phủ", doanh nghiệp tư nhân chỉ có vai trò phối hợp hỗ trợ. Nhưng sau khi ông Donald Trump lên nắm quyền, Mỹ chủ động đẩy các doanh nghiệp sản xuất vũ khí lên phía trước, đồng ý để các doanh nghiệp này trực tiếp đàm phán với Đài Loan. Từ đó, chủ thể tiêu thụ cũng sẽ chuyển từ phương thức "chính quyền chủ đạo, tư nhân phối hợp" trước đây sang phương thức "chính quyền và tư nhân cùng làm, tư nhân đi trước".

Bên cạnh đó, Mỹ lựa chọn những thời điểm nhạy cảm để phê duyệt các thương vụ bán vũ khí cho Đài Loan. Thông qua so sánh thời điểm những lần Mỹ bán vũ khí cho Đài Loan và tình hình quan hệ Mỹ - Trung Quốc đại lục, có thể thấy chính quyền Mỹ thường lựa chọn thời kỳ quan hệ Mỹ - Trung Quốc đại lục tốt đẹp để khởi động một thương vụ bán vũ khí mới cho Đài Loan. Nhưng hiện nay, chính quyền Trump chủ yếu tập trung tối đa hóa lợi ích đàm phán thương mại Mỹ - Trung Quốc đại lục, quan hệ Mỹ - Trung Quốc đại lục đang rơi vào thời kỳ nhạy cảm. Điều đó cho thấy chính quyền Trump không né tránh phản ứng gay gắt của Đại lục và thẳng thắn thừa nhận mối quan hệ hợp tác khăng khít về mặt quân sự giữa Mỹ và chính quyền đảo Đài Loan.

(2) Sự tăng cường lực lượng quân sự của Mỹ qua eo biển Đài Loan.

Nếu như trước đây, dưới thời người tiền nhiệm Barack Obama, tàu chiến Mỹ chỉ tuần tra trung bình khoảng 1 - 3 lần mỗi năm thì số lượt qua lại của tàu chiến Mỹ dưới thời Tổng thống Donald Trump vẫn duy trì và có tăng cường sự qua lại tại eo biển Đài Loan. Năm 2017, tàu chiến Mỹ băng qua eo biển Đài Loan 5 lần, đến năm 2018, số lượt đi qua eo biển này của tàu chiến Mỹ là 3 lần [7]. Đi cùng với các hoạt động tuần tra của tàu chiến Mỹ là khẩu hiệu "tự do hàng hải" và "cam kết của Mỹ đối với một khu vực Ân Độ Dương - Thái Bình Dương tự do và rộng mở", trong đó Đài Loan là một phần không thể thiếu của cam kết ấy.

Mặc dù sự hợp tác về quân sự luôn vấp phải sự phản ứng kịch liệt của Trung Quốc nhưng không vì thế mà các hoạt động này thu hẹp về mặt quy mô và số lượng. Trung Quốc đại lục càng tỏ ra giận dữ thì chính quyền Mỹ càng có lí do để gia tăng các hoạt động quân sự, vì trong cuộc "thư hùng" Mỹ - Trung Quốc đại lục, mỗi bên cần chứng tỏ mình có nhiều quân bài đủ để khiến đối phương phải nhượng bộ.

Khía cạh thư tu, hợp tác thương mại phát triển mạnh mẽ và nối tiếp đà tăng trưởng từ các năm trước đó.

Nếu như giao dịch thương mại giữa Mỹ - Đài Loan năm 2016 đạt hơn 65,1 tỷ USD thì đến năm 2018, giao dịch thương mại đã lên tới hơn 76,3 tỷ USD [2], nghĩa là chỉ sau 2 năm, kim ngạch thương mại hai chiều giữa Mỹ và Đài Loan đã tăng hơn 11 tỷ USD. Sự gia tăng trong kim ngạch thương mại giữa Mỹ và Đài Loan là tất yếu. Đài Loan là nền kinh tế có quy mô lớn thứ 22 thế giới và là đối tác thương mại lớn thứ 11 của nước Mỹ. Nếu so sánh với thời của các Tổng thống tiền nhiệm, sự phát triển thương mại Mỹ - Đài Loan vẫn giữ được tốc độ tăng trưởng tốt.

Tuy nhiên, điều đáng chú ý là trong khi Mỹ đã đánh thuế và đe dọa đánh thuế đối với nhiều nền kinh tế, trong đó có cả những nền kinh tế của các nước đồng minh Mỹ thì Đài Loan lại nhận được ưu ái về thương mại. Không những Đài Loan không bị Tổng thống Donald Trump đánh thuế mà các nhà kinh tế, giới bình luận còn cho rằng Đài Loan là một trong những nơi sẽ được hưởng lợi từ cuộc "thư hùng" thương mại Mỹ - Trung Quốc đại lục [4].

Như vậy, từ những động thái trên, có thể thấy rằng, dưới thời Tổng thống Mỹ Donald Trump, quan hệ Mỹ Đài Loan đã có những bước phát triển mới. Tuy nhiên, sự phát triển trong mối quan hệ Mỹ - Đài Loan không phải là một ngẫu nhiên mà nó nằm trong tính toán chiến lược của chính quyền Donald Trump. Với bản chất của một vị thương nhân và tính cách thực dụng đã ăn sâu vào máu, dường như Tổng thống Donald Trump đã nhìn nhận được những lợi ích từ sự phát triển mối quan hệ Mỹ và Đài Loan. Sở dĩ mối quan hệ Mỹ - Đài Loan phát triển mạnh mẽ kể từ khi ông Donald Trump lên nắm quyền vì:

Thư nhất, Đài Loan là một trong những "nước cờ" của Mỹ trong bàn cờ cạnh tranh chiến lược Mỹ - Trung. 
Dưới thời Tổng thống Donald Trump, nước Mỹ đang chứng kiến một sự chuyển dịch quyền lực lớn trong nền quản trị toàn cầu. Kể từ năm 2010, Trung Quốc đại lục trở thành nền kinh tế thứ hai thế giới, sau Mỹ. Đặc biệt, sau Đại hội XVII (2013) của Đảng Cộng sản Trung Quốc, Trung Quốc thay đổi phương châm từ "giấu mình chờ thời" sang "phấn đấu để thành công" và đề ra hai cột mốc lớn trong tương lai.

Dấu mốc thứ nhất trong tương lai của Trung Quốc là vào năm 2020, một năm trước lễ kỷ niệm 100 năm thành lập Đảng Cộng sản Trung Quốc, nước này sẽ phấn đấu trở thành quốc gia khá giả.

Dấu mốc thứ hai là năm 2049, tròn 100 năm thành lập nước Cộng hòa Nhân dân Trung Hoa, Trung Quốc sẽ vươn lên trở thành quốc gia xã hội chủ nghĩa hiện đại, toàn diện.

Để thực hiện những dấu mốc quan trọng đó, Trung Quốc đề ra học thuyết "Giấc mộng Trung Hoa" và khởi xướng kế hoạch "Nhất đới, nhất lộ" (Một vành đai, một con đường) để cạnh tranh vị thế lãnh đạo của Mỹ, trước hết ở khu vực châu Á - Thái Bình Dương. Đồng thời, trong bối cảnh cuộc cách mạng công nghiệp 4.0 đang phát triển như vũ bão, Trung Quốc đang từng bước làm chủ các ngành công nghệ tương lai với kế hoạch "Made in China 2025”. Lịch sử chứng minh, quốc gia nào làm chủ cuộc cách mạng công nghiệp, quốc gia đó sẽ vươn lên dẫn đầu. Rõ ràng, tham vọng của Trung Quốc đại lục là rất lớn, đặc biệt, tham vọng ấy được thực hiện bởi thế hệ lãnh đạo thứ năm của Trung Quốc, đứng đầu là ông Tập Cận Bình.

Ngay từ khi tranh cử Tổng thống Mỹ, trong tác phẩm "Đã đến lúc cứng rắn để khôi phục sự vĩ đại của nước Mỹ”, ông Donald Trump đã gọi Trung Quốc là "kẻ thù" và "kẻ đang hủy hoại tương lai con cháu mình". Ông đã nhiều lần chỉ trích người tiền nhiệm đã để Trung Quốc lấn lướt và không chỉ những hành động cụ thể để kiềm chế Trung Quốc, và kết quả là "chúng ta đang cắm đầu vào thảm họa kinh tế" [6, tr.20]. Từ đó, ứng cử viên Donald Trump cho rằng vị Tổng thống kế nhiệm ông Barack Obama phải là người "biết cứng rắn với Trung Quốc, biết cách đàm phán thắng Trung Quốc, và làm thế nào để bọn họ đừng giở trò gạt ta hết lần này đến lần khác" [6, tr.18]. Ông tự nhận trách nhiệm nặng nề đó lên vai mình, và cho rằng chỉ có bản thân mới có thể làm được điều kỳ diệu đó. Để thực hiện điều đó, ứng cử viên Donald Trump đề ra khẩu hiệu tranh cử "Make America Great Again" - Làm cho nước Mỹ vĩ đại trở lại. Dường như là Trung Quốc là một trong những đối tượng làm cho nước Mỹ không thể vĩ đại trở lại theo khẩu hiệu tranh cử của ông.

Kể từ khi nắm quyền (20/01/2017), Tổng thống Donald Trump đã đưa ra hàng loạt tuyên bố cứng rắn và những động thái nhanh chóng: đánh thuế hàng hóa Trung Quốc, đưa Trung Quốc vào danh sách các quốc gia thao túng tiền tệ, tuyên bố ủng hộ các cuộc biểu tình của nhân dân Hồng Kong và phát triển mối quan hệ với Đài Loan. Như vậy, Đài Loan là một trong những con át chủ bài trong cuộc "thư hùng" với Trung Quốc. Trong bối cảnh xuất hiện những dấu hiệu cho thấy Trung Quốc đại lục sẽ không nhân nhượng Mỹ, chắc chắn trong thời gian sắp tới chính quyền Donald Trump vẫn sẽ tiếp tục củng cố mối quan hệ với chính quyền đảo Đài Loan.

Thú hai, mối quan hệ Mỹ - Đài Loan còn được thúc đẩy bởi các thế lực thân Đài Loan trong chính quyền Donald Trump. Các thế lực thân Đài Loan là những người đã sắp xếp cuộc điện đàm giữa người lãnh đạo đảo Đài Loan, bà Thái Anh Văn với ông Donald Trump chỉ ít lâu sau khi ông Trump đắc cử Tổng thống Mỹ. Theo Taipei Times, ông Trump được cho là đã đồng ý điện đàm sau khi các trợ lý của ông trình bày sơ qua về các vấn đề liên quan đến Đài Loan cũng như tình hình ở eo biển Đài Loan [5]. Đồng thời, các thế lực thân Đài Loan ở Mỹ tích cực hối thúc chính quyền Donald Trump bán vũ khí tiên tiến cho Đài Loan. Ngày 26/3/2018, Thượng nghị sĩ John Cornyn và James Inhofe đã gửi thư cho Tổng thống Donald Trump, hối thúc Chính phủ Mỹ bán máy bay chiến đấu hiện đại F-35B có khả năng cất và hạ cánh theo chiều thẳng đứng cho Đài Loan, hoặc là bán F-16V nhằm nâng cao năng lực phòng ngự trên không của hòn đảo. Như vậy, các thế lực thân Đài Loan đóng vai trò là chất xúc tác trong quan hệ Mỹ - Đài Loan. Chính các thế lực này đã khiến Tổng thống Donald Trump càng tự tin vào thủ đoạn sử dụng Đài Loan như một quân cờ hữu hiệu trong cuộc cạnh tranh chiến lược Mỹ - Trung.

Thư $b a$, phát triển mối quan hệ Mỹ - Đài Loan mang bản chất chính trị sâu sắc.

Tổng thống Mỹ Donald Trump xuất thân từ Đảng Cộng hòa, một chính đảng của tầng lớp tư bản công nghiệp. Thông qua phát triển mối quan hệ với Đài Loan, Mỹ đã thu về hàng loạt những hợp đồng vũ khí khổng lồ. Các hợp đồng bán vũ khí này đã thúc đẩy tăng trưởng kinh tế Mỹ nói chung và thúc đẩy sản xuất của các doanh nghiệp sản xuất công nghiệp nặng và công nghiệp quốc phòng nói riêng. Qua đó, Tổng thống Donald Trump ngày càng củng cố quyền lực của mình trong Đảng Cộng hòa và thu hút sự ủng hộ của tầng lớp tư bản công nghiệp trong xã hội. Năm 2018, Tổng thống Donald Trump tuyên bố 100\% sẽ tái tranh cử Tổng thống nhiệm kỳ thứ hai [3]. Trong bối cảnh đó, sự ủng hộ của các tầng lớp tư bản trung thành là một trong những yếu tố cần thiết và quan trọng lúc này với ông Trump, được coi là yếu tố nền tảng để ông 
có thể tái đắc cử và trở thành ông chủ nhà Trắng trong 4 năm tiếp theo. Có thể thấy rằng, kịch bản gây căng thẳng để bán vũ khí cho các bên là điều không quá mới lạ trong chiến lược của Mỹ. Do đó, để "đài thọ" cho tầng lớp tư bản công nghiệp, chắc chắn trong thời gian còn lại của nhiệm kỳ đầu tiên, Tổng thống Donald Trump sẽ tiếp tục thúc đẩy mối quan hệ với Đài Loan và phê chuẩn nhiều thương vụ bán vũ khí, tạo ra sự căng thẳng trong quan hệ giữa hai bờ eo biển Đài Loan để chớp thời cơ thu về những hợp đồng vũ khí khổng lồ.

Hơn nữa, trong lưỡng viện Quốc hội Mỹ luôn tồn tại thế lực thân Đài Loan. Kể từ khi nắm quyền, ông Donald Trump đã gặp không ít những rắc rối với nhánh lập pháp trong nền chính trị nước Mỹ, nhất là sau khi Đảng Dân chủ nắm phần lớn ghế trong Hạ viện (11/2018) và cuộc điều tra Tổng thống thông đồng với Nga trong cuộc bầu cử tháng 11/2016. Để bảo vệ bản thân và gia đình, chắc chắn Tổng thống Donald Trump buộc phải nhượng bộ một số chính sách đối các thành viên lưỡng viện Quốc hội, trong đó có cả "thế lực" thân Đài Loan. Ngay cả khi công tố viên đặc biệt James Comey không tìm được bằng chứng ông Trump thông đồng với Nga trong cuộc bầu cử tháng 11/2016, ông Trump vẫn phải đánh đổi để tránh nguy cơ tái luận tội. Do đó, các chính sách với Đài Loan là một phần để duy trì trạng thái cân bằng của nền chính trị Mỹ, vốn đã bị phủ bóng bởi cuộc đấu đá giữa hai chính đảng hợp hiến ở nước này.

Thư tur, mong muốn phát triển mối quan hệ với Mỹ của chính quyền Đài Loan dưới thời nhà lãnh đạo Thái Anh Văn.

Bà Thái Anh Văn xuất thân từ Đảng Dân chủ Tiến bộ (DPP), một chính đảng ủng hộ xu hướng "Đài độc" và tính bản địa của Đài Loan. Trên thực tế, kể từ khi nắm quyền (5/2016), bà Thái Anh Văn đã tuyên bố từ chối công nhận "Nhận thức chung" (1992) giữa hai bờ eo biển Đài Loan và mô hình "một quốc gia, hai chế độ" mà đại lục muốn áp dụng với hòn đảo nơi mà bà lãnh đạo.

Để thực hiện quan điểm của mình, bà Thái Anh Văn đã từ bỏ các chính sách thân Đại lục có từ giai đoạn cầm quyền của người tiền nhiệm xuất thân từ Quốc dân đảng và củng cố mối quan hệ với Mỹ. Điều này là hết sức dễ hiểu, xuất phát từ cục diện tình hình trong tam giác quan hệ Mỹ - Đài - Trung, để bảo vệ hòn đảo của mình, bà Thái Anh Văn buộc phải dựa vào Mỹ mới có thể cân bằng lực lượng với Đại lục. Một yếu tố khác có thể hiểu được, bà Thái Anh Văn là một trí thức nổi tiếng của Đảng Dân tiến, có học hàm Giáo sư và đã tốt nghiệp Thạc sỹ trường Đại học Luật Cornell. Chính sự giáo dục bài bản đã định hướng bà đi theo những giá trị dân chủ, tự do của các nước tư bản phương Tây. Do đó, bà mong muốn phát triển mối quan hệ với Mỹ, nơi mà bà từng gắn bó và được đào tạo trong nhiều năm. Trong quá trình cầm quyền, bà Thái Anh Văn đã rút ra những bài học kinh nghiệm từ những năm tháng cầm quyền của ông Trần Thủy Biển. Vì thế, bà đã có nhiều chính sách làm hài lòng chính quyền Washington.

\section{Kết luận}

Như vậy, trong nửa đầu nhiệm kỳ của Tổng thống Donald Trump, quan hệ Mỹ - Đài Loan đã có những bước phát triển mới. Với bản chất thực dụng đã ăn sâu vào máu, cùng với tư chất tính toán chi ly của một thương nhân dày dạn kinh nghiệm, Tổng thống Donald Trump chắc chắn đã nghiên cứu rất kỹ về những lợi ích mà Mỹ có thể nhận được và mức độ phản ứng của đại lục./.

\section{TÀI LIỆU THAM KHẢO}

1. Caren Boham, David Brunnstrom (2016), Trump says U.S. not necessarily bound by 'one China' policy, Retrieved from

https://www.reuters.com/article/us-usa-trumpchina/trump-says-u-s-not-necessarily-bound-by-onechina-policy-idUSKBN1400TY

2. Wayne M. Morrison (2019), U.S.-Taiwan Trade Relations, Retrieved from

https://fas.org/sgp/crs/row/IF10256.pdf

3. Ánh Ngọc (2018), Trump tuyên bố 100\% tái tranh củ Tổng thống, Truy cập từ

https://vnexpress.net/trump-tuyen-bo-100-tai-tranhcu-tong-thong-3825115.html

4. Ashutosh Pandey (2019), Vietnam, Taiwan winning the US-China trade war, Retrieved from https://www.dw.com/en/vietnam-taiwan-winning-the-uschina-trade-war/a-49068586

5. Minh Phương (tổng hợp) (2016), Ai đã thu xếp cuộc điện đàm giũa ông Trump với lãnh đạo Đài Loan?, Truy cập từ https://dantri.com.vn/the-gioi/ai-da-thu-xep-cuocdien-dam-giua-ong-trump-voi-lanh-dao-dai-loan-

20161206085353541.htm

6. Donald J. Trump, Đã đến lúc phải cứng rắn để khôi phục sư vĩ đại của nuớc Mỹ, Nxb. Thế giới, Hà Nội, 2016, tr. $18,20$.

7. 信任毀於「疫」旦美秀肌肉搏籌碼 (2020), 從訪 問

https://turnnewsapp.com/global/politics/174806.html?fbc lid=IwAR3sCOLO3jmMFAwjWQnVmOzIHNgXYlg3D JtKitpAx9v-OTI89-kGb-PS5sM 


\section{United States -Taiwan relations in the first half term of President Donald Trump}

Nguyen Duc Manh

\section{Article info}

Recieved:

4/5/2020

Accepted:

$10 / 6 / 2020$

Keywords:

United States, Taiwan,

Donald Trump, Thai Anh

Van, external relations.

\begin{abstract}
The relationship between the United States and Taiwan has always been the diplomatic relationship which has been interested by American presidents. This relationship continued to be strengthened and developed under President Donald Trump, even making great changes. In the article, the author analyzes the development of US and Taiwan relations in the first half term of President Donald Trump (20172018), so the author can give some reasons of these changes.
\end{abstract}

